\title{
Preoperative anaemia and perioperative red blood cell transfusion as prognostic factors for recurrence and mortality in colorectal cancer-a Swedish cohort study
}

\author{
Malin E. M. Mörner ${ }^{1,2}$ • Gustaf Edgren ${ }^{3}$ • Anna Martling ${ }^{4,5}$ • Ulf Gunnarsson ${ }^{6}$ • \\ Monika Egenvall ${ }^{4,5}$
}

Accepted: 10 October 2016/Published online: 21 October 2016

(C) The Author(s) 2016. This article is published with open access at Springerlink.com

\begin{abstract}
Purpose The hypothesis in this study was that anaemia prior to surgery and perioperative red blood cell transfusion increases the risk for recurrence and overall mortality in patients with stages I-III colorectal cancer after abdominal resection with curative intent.

Methods This is a Swedish single centre retrospective cohort study. Data on 496 consecutive radical abdominal resections stages I-III colorectal cancer performed at the Karolinska University Hospital 2007-2010 were extracted from the Swedish Colorectal Cancer Registry. Data were linked to local laboratory and transfusion databases to identify preoperative anaemia and perioperative transfusion. Disease recurrence was validated by scrutiny of patient records. A total of 496 stages I-III colorectal cancer patients were included in the analysis. Multivariate Cox regression analysis adjusted for tumour and patient characteristics were performed to assess risk for recurrence and overall mortality.

Results Anaemia prior to surgery was associated with increased risk for overall mortality (HR 2.1, 95\% CI 1.4-3.2).
\end{abstract}

There was no association between anaemia and risk for recurrence (HR 1.6, 95\% CI 0.97-2.6). Transfusion was not associated with increased risk of recurrence (HR 0.7, 95\% CI 0.41.3 ) or overall mortality (HR 1.04, 95\% CI 0.7-1.6).

Conclusions Anaemia prior to colorectal cancer surgery was associated with increased risk for overall mortality while a no increased risk was seen for recurrence. Previous findings indicating an association between blood transfusion and increased risk for recurrence could not be confirmed.

Keywords Anaemia - Transfusion · Colorectal cancer · Recurrence $\cdot$ Mortality $\cdot$ Survival

\section{Introduction}

Anaemia is common in colorectal cancer [1-3] (CRC), with a reported prevalence ranging from 23 to $75 \%$ [1-4]. Worldwide, CRC is the third most common cancer in men and second most common in women [5]. Iron deficiency
Malin E. M. Mörner

malin.morner@ki.se

Gustaf Edgren

Gustaf.edgren@ki.se

Anna Martling

Anna.martling@ki.se

Ulf Gunnarsson

Ulf.gunnarsson@umu.se

Monika Egenvall

Monika.egenvall@ki.se
1 Department of Clinical Science Intervention and Technology, Karolinska Institutet, Stockholm, Sweden

2 Functional Area of Emergency Medicine Huddinge, C1:63, Karolinska University Hospital, Huddinge, 141 86 Stockholm, Sweden

3 Department of Medical Epidemiology and Biostatistics, Karolinska Institutet, Stockholm, Sweden

4 Department of Molecular Medicine and Surgery, Karolinska Institutet, Stockholm, Sweden

5 Center of Digestive Diseases, P9:03, Karolinska University Hospital, Solna, Sweden

6 Department of Surgical and Perioperative Sciences, Umeå university, Umeå, Sweden 
anaemia in CRC thus constitutes an important clinical problem with no clear guidelines for management. Anaemia in CRC patients is mainly caused by bleeding from the tumour; either occultly from a proximal colon tumour [2, 6], or with visible faecal blood from distal colon tumours or rectal cancers $[2,7]$. However, anaemia can also be caused by a systemic inflammatory response to the tumour [8].

Iron deficiency anaemia can be corrected by blood transfusion or by the administration of iron medication prior to surgery [9]. Perioperative blood transfusion is considered to be associated with an increased risk for recurrence in CRC patients operated with curative intent [10]. This dose-dependent negative effect was independent of stage or when, during the perioperative period, the transfusion was administered [10].

The importance of anaemia in patients with CRC has only been investigated in a few studies. Anaemia has been associated with more advanced stage [11] and higher mortality [11, 12]. In another study on patients with T3NOM0 and T4NOMO colon cancer, impaired disease-free survival associated with anaemia was only seen in the former group [13].

The hypothesis tested in this study was that preoperative anaemia and perioperative red blood cell transfusion, in patients with localised CRC undergoing curative resection, increase the risk for recurrence and overall mortality.

\section{Materials and methods}

\section{Data sources}

This is a single centre, retrospective cohort study, on resections for CRC stages I-III performed at the Karolinska University Hospital 2007-2010. Data on all consecutive patients living in the region were retrieved from the Swedish Colorectal Cancer Registry (SCRCR) [14, 15] on 7 January 2014. Data were not retrieved on patients referred from other regions since they are followed up where they live. The SCRCR, including prospectively collected data, contains information on the patient, neoadjuvant treatment, surgical procedure, tumour characteristics, and short- and long-term follow-up. Information on all red cell concentrate transfusions was obtained from the local blood transfusion database [16], and on all preoperative haemoglobin concentrations from the local laboratory database. For patients with no available records in the laboratory database $(n=21)$, data on preoperative haemoglobin concentrations were obtained through review of case records. Information on recurrence was validated by scrutiny of patient records and entered into a common database. Record linkage was performed using the patient's unique national registration number assigned to all Swedish citizens upon birth or immigration [17]. After local processing, records from the SCRCR, transfusion and laboratory databases were submitted to the Swedish National Board of Health and Welfare for further record linkage with data not used in this study and anonymisation of the database.

Only resections judged as locally radical and curative by the surgeon and radical by the pathologist (R0) were included (leaving 546 patients). Patients previously operated for CRC $(n=12)$ or operated for metachronous CRCs $(n=16)$ during the study period were excluded. Patients dying during the initial 30 days after surgery or within the same hospital stay if longer $(n=14)$ and patients with missing haemoglobin values $(n=8)$ were also excluded leaving 496 patients for the final analysis: 282 colon cancers and 214 rectal cancers.

Main outcomes were recurrence and overall death.

Anaemia was defined according to the WHO classification of anaemia for the adult population (age $\geq 15$ years); a haemoglobin less than $120 \mathrm{~g} / \mathrm{l}$ in non-pregnant women and a haemoglobin less than $130 \mathrm{~g} / 1$ in men [18] within 2 months before the date of surgery. Transfusion was defined as having received at least one allogeneic red blood cell transfusion within 1 day of surgery. Analyses were also performed for patients receiving a transfusion within 30 days of surgery. Operations were classified and divided into three groups: colon resection, low anterior resection and Hartmann's procedure (for rectal cancer) and a third group with abdomino-perineal resection.

A local recurrence or metastases diagnosed by radiology or histopathology and verified by viewing the patient records was defined as a recurrence.

\section{Statistical analysis}

Categorical variables were described as frequency and percentages. Age was described as median with interquartile range (IQR).

Differences in the distribution of gender, tumour site, ASA class, pT Stage and pN stage between patients with and without anaemia were analysed using the chi-square test. Multivariate adjusted analyses were performed using the Cox Proportional Hazards model for calculation of Hazard ratios. The multivariate analyses were adjusted for parameters suspected of being associated both with anaemia/transfusion and risk for recurrence and overall mortality; gender, ASA class, pT Stage, pN Stage, type of surgery and neo-adjuvant treatment, all as categorical variables, and for age and blood loss as restricted cubic splines with three degrees of freedom [19, 20]. This made it possible to adjust for age and blood loss as functions of continuous variables.

In the analysis of risk for recurrence, patients were followed from the date of surgery until the date of first 
recurrence, death or end of follow-up (2014-01-07), whichever came first. In the analysis of overall mortality, patients were followed from the date of surgery until date of death, or end of follow-up (2014-01-07), whichever came first. Data are presented as hazard ratios (HR) with $95 \%$ confidence intervals (CI). Relative risk is used in the text as being equivalent to hazard ratio.

To assess the appropriateness of including both anaemia and transfusion in the same regression model, co-linearity between these variables was tested using the chi-square test. This analysis revealed some evidence of moderately strong co-linearity, and we therefore conducted separate analyses and analyses with both variables in the same model.

Table 1 Patient characteristics of 496 patients undergoing curative abdominal resections for stage I-III colorectal cancer

\begin{tabular}{|c|c|c|}
\hline Patient characteristics & No anaemia & Anaemia \\
\hline Subjects, $N$ (\% of total) & $239(48.2)$ & $257(51.8)$ \\
\hline Female, $N(\%)$ & $115(48.1)$ & $119(46.3)$ \\
\hline Median age (year) at diagnosis ${ }^{\mathrm{a}}$ (IQR) & $67(61-74)$ & $70(62-79)$ \\
\hline \multicolumn{3}{|l|}{ Number CRC, no. $(\%)$} \\
\hline Colon & $115(48.1)$ & $167(65.0)$ \\
\hline Rectum & $124(51.9)$ & $90(35.0)$ \\
\hline \multicolumn{3}{|l|}{ ASA, $N(\%)$} \\
\hline 1 & $50(20.9)$ & $30(11.7)$ \\
\hline 2 & $132(55.2)$ & $113(44.0)$ \\
\hline 3 & $48(20.1)$ & $100(38.9)$ \\
\hline 4 & $9(3.8)$ & $14(5.4)$ \\
\hline \multicolumn{3}{|l|}{ pT stage, $N(\%)$} \\
\hline 1 & $43(18.0)$ & $14(5.4)$ \\
\hline 2 & $66(27.6)$ & $27(10.5)$ \\
\hline 3 & $109(45.6)$ & $154(59.9)$ \\
\hline 4 & $21(8.8)$ & $62(24.1)$ \\
\hline \multicolumn{3}{|l|}{ pN stage, $N(\%)$} \\
\hline 0 & $173(72.4)$ & $178(69.3)$ \\
\hline 1 & $51(21.3)$ & $50(19.5)$ \\
\hline 2 & $15(6.3)$ & $29(11.3)$ \\
\hline \multicolumn{3}{|l|}{ Type of surgery, N (\%) } \\
\hline Colon resection & $115(48.1)$ & $166(64.6)$ \\
\hline Low anterior resection + Hartmann $^{\mathrm{b}}$ & $83(34.7)$ & $50(19.5)$ \\
\hline Abdomino-perineal resection ${ }^{\mathrm{c}}$ & $41(17.2)$ & $41(16.0)$ \\
\hline \multicolumn{3}{|l|}{ Neo-adjuvant treatment, $N(\%)$} \\
\hline (Chemo) radiotherapy ${ }^{\mathrm{b}}$ & $99(79.8)$ & $73(81.1)$ \\
\hline Chemotherapy only & $1(0.4)$ & $6(2.3)$ \\
\hline
\end{tabular}

All percentages are given as percentage of number of patients within group for no anaemia/anaemia unless stated otherwise

${ }^{a}$ Median age patients with colon cancer 71 years, median age patients with rectal cancer 65 years

${ }^{\mathrm{b}}$ Only patients with rectal cancers

${ }^{\mathrm{c}}$ Including one patient with colon cancer in the anaemic group
Kaplan-Meyer curves showing risk for recurrence and overall survival were compared with log-rank test to test for significant differences between groups.

A $p$ value $<0.05$ was considered statistically significant. STATA/IC 11.2 was used for statistical analyses and figures.

\section{Results}

Patient characteristics according to grade of anaemia and blood transfusion are given in Tables 1 and 2. Of the anaemic patients, $150(58 \%)$ received a transfusion within $24 \mathrm{~h}$ of surgery compared to $49(21 \%)$ of the non-

Table 2 Patient characteristics of 496 patients undergoing curative abdominal resections for stage I-III colorectal cancer

\begin{tabular}{|c|c|c|}
\hline Patient characteristics & No transfusion & Transfusion \\
\hline Subjects, $N$ (\% of total) & $297(59.9)$ & $199(40.1)$ \\
\hline Female, $N(\%)$ & $136(45.8)$ & $98(49.2)$ \\
\hline Median age (year) at diagnosis ${ }^{\mathrm{a}}$ (IQR) & $66(61-73)$ & $73(63-80)$ \\
\hline \multicolumn{3}{|l|}{ Number CRC, no. (\%) } \\
\hline Colon & $173(58.2)$ & $109(54.8)$ \\
\hline Rectum & $124(41.8)$ & $90(45.2)$ \\
\hline \multicolumn{3}{|l|}{ ASA, $N(\%)$} \\
\hline 1 & $70(23.6)$ & $10(5.0)$ \\
\hline 2 & $149(50.2)$ & $96(48.2)$ \\
\hline 3 & $70(23.6)$ & $78(39.2)$ \\
\hline 4 & $8(2.7)$ & $15(7.5)$ \\
\hline \multicolumn{3}{|l|}{ pT stage, $N(\%)$} \\
\hline 1 & $43(14.5)$ & $14(7.0)$ \\
\hline 2 & $67(22.6)$ & $26(13.1)$ \\
\hline 3 & $155(52.2)$ & $108(54.3)$ \\
\hline 4 & $32(10.8)$ & $51(25.6)$ \\
\hline \multicolumn{3}{|l|}{ pN stage, $N(\%)$} \\
\hline 0 & $213(71.7)$ & $138(69.3)$ \\
\hline 1 & $59(19.9)$ & $42(21.1)$ \\
\hline 2 & $25(8.4)$ & $19(9.5)$ \\
\hline \multicolumn{3}{|l|}{ Type of surgery, $N(\%)$} \\
\hline Colon resection & $173(58.2)$ & $108(54.3)$ \\
\hline Low anterior resection + Hartmann $^{\mathrm{b}}$ & $82(27.6)$ & $51(25.6)$ \\
\hline Abdomino-perineal resection $^{\mathrm{c}}$ & $42(14.1)$ & $40(20.1)$ \\
\hline \multicolumn{3}{|l|}{ Neo-adjuvant treatment, $N(\%)$} \\
\hline (Chemo) radiotherapy ${ }^{\mathrm{b}}$ & $97(78.2)$ & $75(83.3)$ \\
\hline Chemotherapy only & $3(1.0)$ & $4(2.0)$ \\
\hline
\end{tabular}

All percentages are given as percentage of number of patients within group (not transfused/transfused within $24 \mathrm{~h}$ before or after surgery) unless stated otherwise

${ }^{\mathrm{a}}$ Median age patients with colon cancer 71 years, median age patients with rectal cancer 65 years

${ }^{\mathrm{b}}$ Only patients with rectal cancers

${ }^{\mathrm{c}}$ Including one patient with colon cancer for the transfused patients 
Fig. 1 Proportion of patients, operated for CRC stages I-III, without recurrence divided in patients with preoperative anaemia and no anaemia. $p$ value represents log-rank test

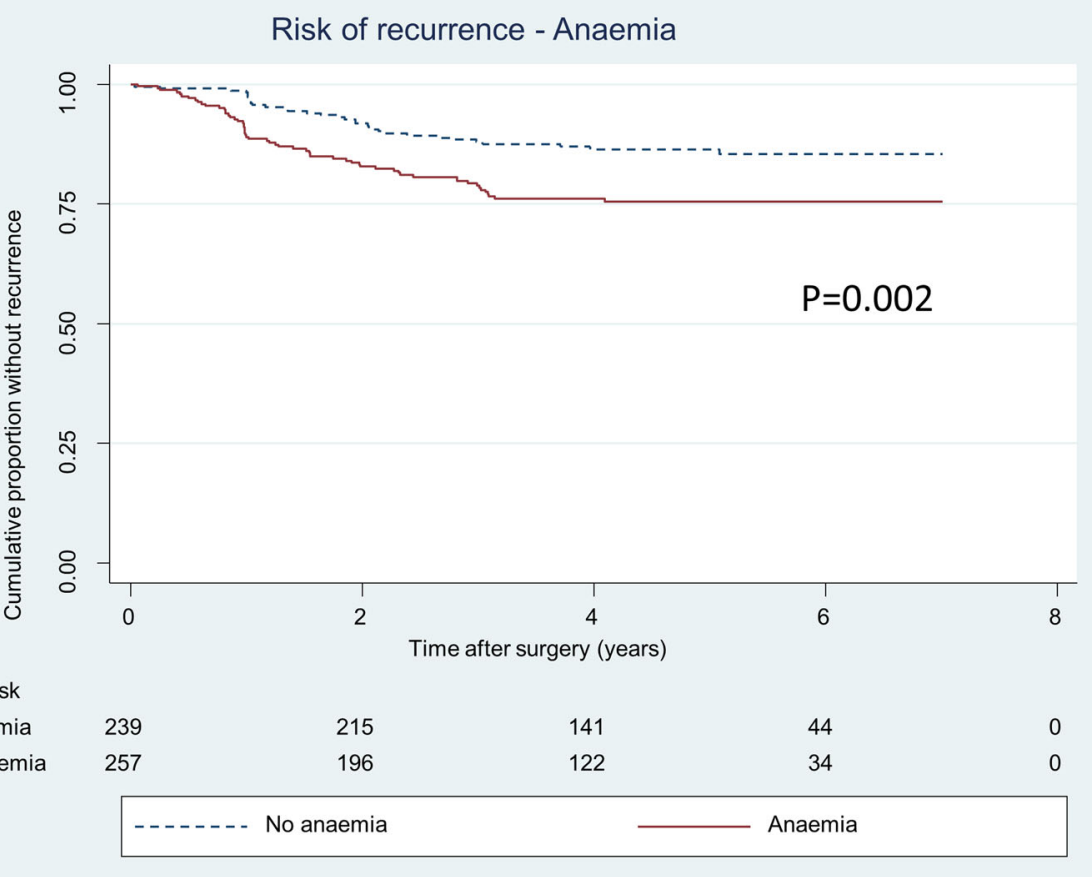

anaemic patients. In total, 199 patients in the cohort received a red cell blood transfusion within $24 \mathrm{~h}$ of their resection. In addition, 46 patients received transfusion more than $24 \mathrm{~h}$ before or after surgery within 30 days before or after surgery.

Colon cancer, more advanced ASA class and pT Stage were all significantly associated with anaemia $(p<0.001)$ whereas gender $(p=0.69)$ and $\mathrm{pN}$ stage $(p=0.14)$ were not significantly associated with anaemia.

The log-rank test analysis revealed that patients suffering from anaemia prior to surgery had a significantly increased risk for recurrence ( $p=0.002)$ (Fig. 1), while the multivariate model with anaemia as dependent variable was not significant (HR 1.6, 95\% CI 0.97-2.6). There was no association between receiving blood transfusion within $24 \mathrm{~h}$ of surgery and risk for recurrent disease (HR 0.7, 95\% CI, 0.4-1.3) (Table 3, Fig. 2). Multivariate Cox regression analysis was also conducted for patients receiving a transfusion within 30 days of surgery (HR $0.7,95 \%$ CI 0.4-1.2).

Anaemia prior to surgery was also associated with poorer overall survival (HR 2.1, 95\% CI 1.4-3.2) (Table 4, Fig. 3). There was no association between blood transfusion and overall survival in the multivariate Cox regression analysis (HR 1.04, 95\% CI 0.7-1.6) (Table 4) while the survival analysis tested with log-rank test was significant (Fig. 4).

The analysis including both anaemia and transfusion as independent variables in the same model revealed an association between anaemia and risk for recurrence (HR 1.7, 95\% CI 1.1-2.9) (Table 3), and death (HR 2.3, 95\% CI 1.5-3.6)
(Table 4). There was no association between transfusion and either of these outcomes (Table 3, Table 4).

\section{Discussion}

Preoperative anaemia, present in approximately $50 \%$ of the CRC patients in this study, was a strong predictor for impaired survival. There was no significantly increased risk of cancer recurrence in patients with preoperative anaemia. Blood transfusion was neither associated with increased risk for recurrence, nor with overall mortality in the present study.

This is a single centre retrospective cohort study using prospectively registered registry data. Consecutive patients undergoing radical abdominal resection for stages I-III CRC at the Karolinska University Hospital and living in the region were included. The minimum follow-up time in the study was 3 years. Karolinska University Hospital is one of the largest centres in Sweden, taking advanced cases from the Stockholm Region. Patients referred from other regions were not included in the trial since they are followed up at their nearest hospital.

For each patient, the lowest of all haemoglobin values registered within 2 months before the date of surgery was chosen for classification of anaemia. This was to minimise the risk of patients receiving preoperative iron medication or blood transfusion and being misclassified.

Data on blood transfusion was collected 2 months before surgery until 1 month after surgery. Analyses were performed 
Table 3 Multivariate Cox regression analysis for risk of recurrence of 496 patients undergoing curative abdominal resections for stages I-III colorectal cancer

\begin{tabular}{|c|c|c|c|c|}
\hline & Events/person-years & $\begin{array}{l}\text { Preoperative anaemia } \\
\text { Hazard ratio }(95 \% \mathrm{CI})\end{array}$ & $\begin{array}{l}\text { Transfusion ( } \pm 1 \text { day) } \\
\text { Hazard ratio ( } 95 \% \mathrm{CI})\end{array}$ & $\begin{array}{l}\text { Preoperative anaemia } \\
\text { and transfusion } \\
\text { Hazard ratio }(95 \% \mathrm{CI})\end{array}$ \\
\hline \multicolumn{5}{|l|}{ Anaemia } \\
\hline Yes & $58 / 953.8$ & $1.6(0.97-2.6) \mathrm{ns}$ & & $1.7(1.1-2.9)^{*}$ \\
\hline No & $32 / 1046.6$ & 1.00 (ref) & & 1.00 (ref) \\
\hline \multicolumn{5}{|l|}{ Transfusion } \\
\hline Red blood cell & $35 / 792.5$ & & $0.7(0.4-1.3) \mathrm{ns}$ & $0.6(0.4-1.1) \mathrm{ns}$ \\
\hline No transfusion & $55 / 1207.9$ & & 1.00 (ref) & 1.00 (ref) \\
\hline \multicolumn{5}{|l|}{ Sex } \\
\hline Female & $39 / 983.8$ & $0.8(0.5-1.2) \mathrm{ns}$ & $0.8(0.5-1.3) \mathrm{ns}$ & $0.8(0.5-1.4) \mathrm{ns}$ \\
\hline Male & $51 / 1016.6$ & 1.00 (ref) & 1.00 (ref) & 1.00 (ref) \\
\hline \multicolumn{5}{|l|}{ ASA grade } \\
\hline 1 & $20 / 329.5$ & 1.00 (ref) & 1.00 (ref) & 1.00 (ref) \\
\hline 2 & $43 / 1052.3$ & $0.9(0.5-1.6) \mathrm{ns}$ & $0.9(0.5-1.8) \mathrm{ns}$ & $0.9(0.5-1.8) \mathrm{ns}$ \\
\hline 3 & $23 / 539.1$ & $0.7(0.3-1.5) \mathrm{ns}$ & $0.9(0.4-1.8) \mathrm{ns}$ & $0.8(0.4-1.8) \mathrm{ns}$ \\
\hline 4 & $4 / 79.6$ & $1.4(0.4-4.6) \mathrm{ns}$ & $1.8(0.5-6) \mathrm{ns}$ & $1.8(0.5-6.1) \mathrm{ns}$ \\
\hline \multicolumn{5}{|l|}{$\mathrm{pT}$} \\
\hline 1 & $2 / 264.7$ & 1.00 (ref) & 1.00 (ref) & 1.00 (ref) \\
\hline 2 & $7 / 388.8$ & $1.7(0.3-8.3) \mathrm{ns}$ & $1.6(0.3-8) \mathrm{ns}$ & $1.6(0.3-7.9) \mathrm{ns}$ \\
\hline 3 & $49 / 1054.7$ & $4.9(1.2-20.6)^{*}$ & $5.4(1.3-22.6)^{*}$ & $4.7(1.1-19.9)^{*}$ \\
\hline 4 & $32 / 292.2$ & $12.3(2.8-53.8) * *$ & $15.9(3.7-68.1)^{* * *}$ & $12.3(2.8-53.5)^{* *}$ \\
\hline \multicolumn{5}{|l|}{$\mathrm{pN}$} \\
\hline 0 & $48 / 1466.1$ & 1.00 (ref) & 1.00 (ref) & 1.00 (ref) \\
\hline 1 & $17 / 420.4$ & $1.3(0.7-2.3) \mathrm{ns}$ & $1.3(0.7-2.3) \mathrm{ns}$ & $1.3(0.8-2.4) \mathrm{ns}$ \\
\hline 2 & $25 / 113.9$ & $4.7(2.8-8)^{* * *}$ & $4.8(2.9-8.2)^{* * *}$ & $5(3-8.5)^{* * *}$ \\
\hline \multicolumn{5}{|l|}{ Type of surgery } \\
\hline Colon resection & $38 / 1127.8$ & 1.00 (ref) & 1.00 (ref) & 1.00 (ref) \\
\hline Low anterior resection + Hartmann & $31 / 556.1$ & $2.1(0.9-5) \mathrm{ns}$ & $1.9(0.8-4.6) \mathrm{ns}$ & $2(0.8-4.9) \mathrm{ns}$ \\
\hline Abdomino-perineal resection & $21 / 316.4$ & $2.3(0.9-6.1) \mathrm{ns}$ & $2.2(0.8-6.1) \mathrm{ns}$ & $2.1(0.8-5.8) \mathrm{ns}$ \\
\hline \multicolumn{5}{|l|}{ Neo-adjuvant treatment } \\
\hline Yes & $46 / 714.5$ & $1.4(0.6-3.1) \mathrm{ns}$ & $1.4(0.6-3.1) \mathrm{ns}$ & $1.4(0.6-3.2) \mathrm{ns}$ \\
\hline No & $44 / 1285.9$ & 1.00 (ref) & 1.00 (ref) & 1.00 (ref) \\
\hline
\end{tabular}

Analyses adjusted for age and blood loss as restricted cubic splines, $3 \mathrm{df}$ $n s$ not significant, $r e f$ reference

$* p<0.05 ; * * p<0.01 ; * * * p<0.001$

for patients receiving blood transfusions within 1 day before or after surgery, since this time interval was considered the most interesting period with respect to impaired immunological response of the patient at the time of surgical trauma. One hundred ninety-nine patients ( $81 \%$ of patients receiving blood transfusion) did so within this time interval. It can be argued that the immunological effect of blood transfusion in combination with surgical stress can be longer. Additional analyses for the period 1 month before or after surgery were performed regarding recurrent disease and survival.

The only available measure of co-morbidity was ASA class. This factor was adjusted for in the multivariate models since it was suspected to influence both survival and the risk for anaemia.

Abdomino-perineal resection is known to be associated with a higher risk for recurrence [21], hence the analyses were adjusted for surgical procedure. Although, such an association could not be shown in the current study. Analyses were also performed when dividing colonic resections into acute and elective procedures [22]. This did not affect the outcome estimates, and colon resections were thus analysed as one group.

The stage reported to the SCRCR is the stage derived from examination of the pathology specimen. Since 
Fig. 2 Proportion of patients, operated for CRC stages I-III, without recurrence divided in patients receiving blood transfusion within a day before or after surgery or not. $p$ value represents log-rank test

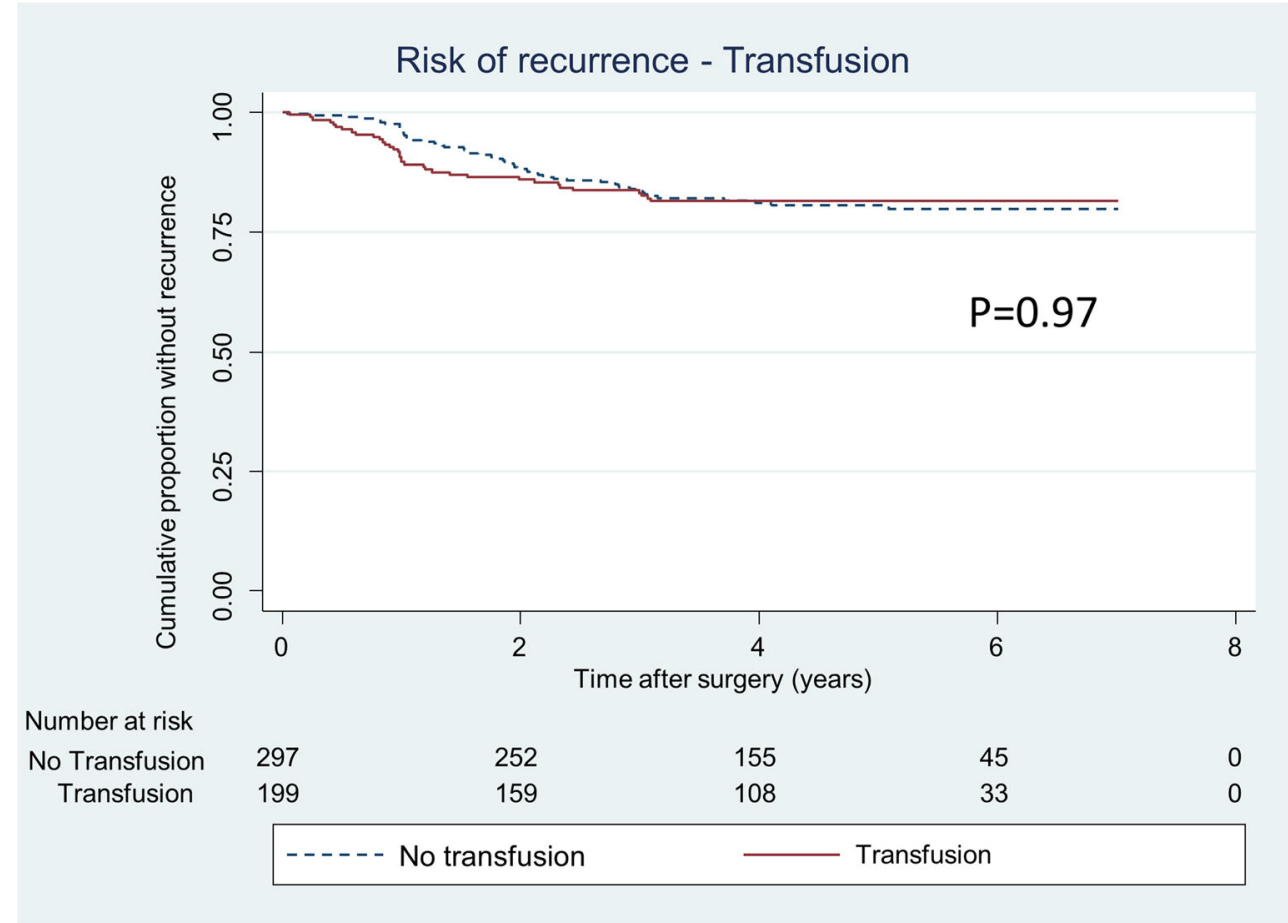

$80 \%$ of the patients with rectal cancer received neoadjuvant (chemo) radiotherapy, and in total $36 \%$ of all patients received any neo-adjuvant oncological treatment, down staging might have occurred in about a third of patients.

The risk for recurrence was associated with preoperative anaemia in the log-rank test but the confidence interval in the multivariate analysis did just include 1 (0.97-2.6) and was thus not significant. However, anaemia was significantly associated with the risk for recurrence in the model including both anaemia and transfusion. Therefore, this could be described as a trend and possibly this would have been significant in both models if the sample size was larger. More advanced $\mathrm{T}$ and $\mathrm{N}$ stage was associated with an increased risk for recurrence in the multivariate model. The association between anaemia and risk for recurrence has previously been shown in a recent study on stage II CRCs where anaemia was shown to be associated with a reduction in recurrence-free survival in T3N0M0 colon cancer patients only, but not in patients with T4N0M0 colon cancers [13]. In that study, adjustment was made for tumour but not for patient characteristics.

Blood transfusion, often defined in studies as given within 30 days before and after surgery, has repeatedly been found to be associated with an increased risk for recurrence [10]. Although there is little specific data on the mechanisms behind such an association, it has typically been attributed to the immunological side effects of blood transfusion [23]. The recurrence risk described previously was independent of tumour stage or when the transfusion was administered [10]. In the present study, no association was found between transfusion and risk for recurrence. The effect of transfusions administered within a day or 30 days before or after surgery showed practically identical results.

Anaemia prior to surgery, gender, ASA and $\mathrm{pN}$-stage class were significantly associated with increased overall mortality regardless of tumour stage. The present study only included CRC patients stages I-III with curative abdominal resection, where all early postoperative deaths were excluded, making the cohort homogenous. Anaemia was associated with increased overall mortality in both the analysis for anaemia alone and in the combined analysis for anaemia and transfusion. The multivariate analyses revealed no association between transfusion and increased overall mortality although the logrank test of the univariate Kaplan-Meyer model was significant.

Little is known about preoperative anaemia and the risk for death in patients operated for CRC [11-13]. Previous studies have shown an association between mild anaemia preoperatively and reduced overall survival 3-8 years after surgery in patients with CRC stages I-IV [12]. That study focused on the association between preoperative symptoms and survival [12]. Mild anaemia was associated with a more advanced stage but stage was not entered into the multivariate analyses 
Table 4 Multivariate Cox regression analysis for overall mortality of 496 patients undergoing curative abdominal resections for stage I-III colorectal cancer

\begin{tabular}{|c|c|c|c|c|}
\hline & $\begin{array}{l}\text { Events/ } \\
\text { person-years }\end{array}$ & $\begin{array}{l}\text { Preoperative } \\
\text { anaemia } \\
\text { Hazard ratio } \\
(95 \% \mathrm{CI})\end{array}$ & $\begin{array}{l}\text { Transfusion } \\
\text { ( } \pm 1 \text { day) } \\
\text { Hazard ratio } \\
(95 \% \mathrm{CI})\end{array}$ & $\begin{array}{l}\text { Preoperative anaemia } \\
\text { and transfusion } \\
\text { Hazard ratio } \\
(95 \% \mathrm{CI})\end{array}$ \\
\hline \multicolumn{5}{|l|}{ Anaemia } \\
\hline Yes & $95 / 1058.5$ & $2.1(1.4-3.2)^{* *}$ & & $2.3(1.5-3.6)^{* * *}$ \\
\hline No & $36 / 1129.4$ & 1.00 (ref) & & 1.00 (ref) \\
\hline \multicolumn{5}{|l|}{ Transfusion } \\
\hline Red blood cell & $67 / 848$ & & $1.04(0.7-1.6) \mathrm{ns}$ & $0.8(0.5-1.2) \mathrm{ns}$ \\
\hline No transfusion & $64 / 1339.9$ & & 1.00 (ref) & 1.00 (ref) \\
\hline \multicolumn{5}{|l|}{ Sex } \\
\hline Female & $53 / 1066.9$ & $0.6(0.4-0.9)^{*}$ & $0.6(0.4-0.9)^{* *}$ & $0.6(0.4-0.9)^{*}$ \\
\hline Male & $78 / 1121$ & 1.00 (ref) & & 1.00 (ref) \\
\hline \multicolumn{5}{|l|}{ ASA grade } \\
\hline 1 & $11 / 382.3$ & 1.00 (ref) & 1.00 (ref) & 1.00 (ref) \\
\hline 2 & $49 / 1147$ & $1.1(0.5-2.3) \mathrm{ns}$ & $1.2(0.6-2.4) \mathrm{ns}$ & $1.1(0.5-2.4) \mathrm{ns}$ \\
\hline 3 & $57 / 576.8$ & $1.9(0.9-4.1) \mathrm{ns}$ & $2.2(1-4.7)^{*}$ & $2(0.96-4.4) \mathrm{ns}$ \\
\hline 4 & $14 / 81.7$ & $3.8(1.6-9.2)^{* *}$ & $4(1.6-10)^{* *}$ & $4.3(1.7-10.6)^{* *}$ \\
\hline \multicolumn{5}{|l|}{$\mathrm{pT}$} \\
\hline 1 & $5 / 270.2$ & 1.00 (ref) & 1.00 (ref) & 1.00 (ref) \\
\hline 2 & $23 / 411.5$ & $2.3(0.8-6) \mathrm{ns}$ & $2.3(0.9-6.2) \mathrm{ns}$ & $2.2(0.8-6) \mathrm{ns}$ \\
\hline 3 & $68 / 1163.5$ & $1.4(0.6-3.6) \mathrm{ns}$ & $1.8(0.7-4.5) \mathrm{ns}$ & $1.4(0.6-3.7) \mathrm{ns}$ \\
\hline 4 & $35 / 342.7$ & $1.8(0.7-5) \mathrm{ns}$ & $2.5(0.9-6.7) \mathrm{ns}$ & $1.9(0.7-5.1) \mathrm{ns}$ \\
\hline \multicolumn{5}{|l|}{$\mathrm{pN}$} \\
\hline 0 & $86 / 1565.1$ & 1.00 (ref) & 1.00 (ref) & 1.00 (ref) \\
\hline 1 & $20 / 463.8$ & $0.8(0.5-1.4) \mathrm{ns}$ & $0.9(0.5-1.4) \mathrm{ns}$ & $0.8(0.5-1.4) \mathrm{ns}$ \\
\hline 2 & $25 / 159$ & $3.6(2.2-5.8) * * *$ & $3.8(2.3-6.1) * * *$ & $3.6(2.2-5.9)^{* * *}$ \\
\hline \multicolumn{5}{|l|}{ Type of surgery } \\
\hline Colon resection & $84 / 1187.7$ & 1.00 (ref) & 1.00 (ref) & 1.00 (ref) \\
\hline $\begin{array}{l}\text { Low anterior } \\
\text { resection }+ \text { Hartmann }\end{array}$ & $24 / 642$ & $0.6(0.3-1.2) \mathrm{ns}$ & $0.5(0.2-1.1) \mathrm{ns}$ & $0.5(0.3-1.1) \mathrm{ns}$ \\
\hline $\begin{array}{l}\text { Abdomino-perineal } \\
\text { resection }\end{array}$ & $23 / 358.2$ & $0.8(0.3-1.8) \mathrm{ns}$ & $0.7(0.3-1.8) \mathrm{ns}$ & $0.7(0.3-1.7) \mathrm{ns}$ \\
\hline \multicolumn{5}{|l|}{ Neo-adjuvant treatment } \\
\hline Yes & $40 / 820.8$ & $1.4(0.7-3) \mathrm{ns}$ & $1.4(0.7-3) \mathrm{ns}$ & $1.5(0.7-3.1) \mathrm{ns}$ \\
\hline No & $91 / 1367.1$ & 1.00 (ref) & 1.00 (ref) & 1.00 (ref) \\
\hline
\end{tabular}

Analyses adjusted for age and blood loss as restricted cubic splines, $3 \mathrm{df}$ $* p<0.05 ; * * p<0.01 ; * * * p<0.001$
[12]. The negative effect of preoperative anaemia on survival was also confirmed in another study including patients after both curative and palliative surgery [11].

Hazard ratios were virtually unaffected when analysing anaemia and transfusion as independent variables in the various multivariate models compared to HRs in the combined model although the association between anaemia and recurrence did not reach statistical significance in the model including only anaemia. Preoperative anaemia was, in both models, a significant risk factor for overall mortality. We were unable to show that transfusion has an impact on these outcomes in the multivariate models. It can be argued not to include both anaemia and blood transfusion in the same model since they are dependent of each other but, we believe, that showing both the separate models and the combined model increases the robustness of the results. The results of the present study stand in stark contrast to the conclusions of two meta-analyses where perioperative blood transfusion was considered to be consistently associated with risk for recurrence [10, 24]. One possible explanation could be that the Karolinska University hospital began using leucocyte-depleted blood components in 1997, so that all patients included 
Fig. 3 Proportion of patients, operated for CRC stages I-III, alive divided in patients with preoperative anaemia and no anaemia. $p$ value represents logrank test

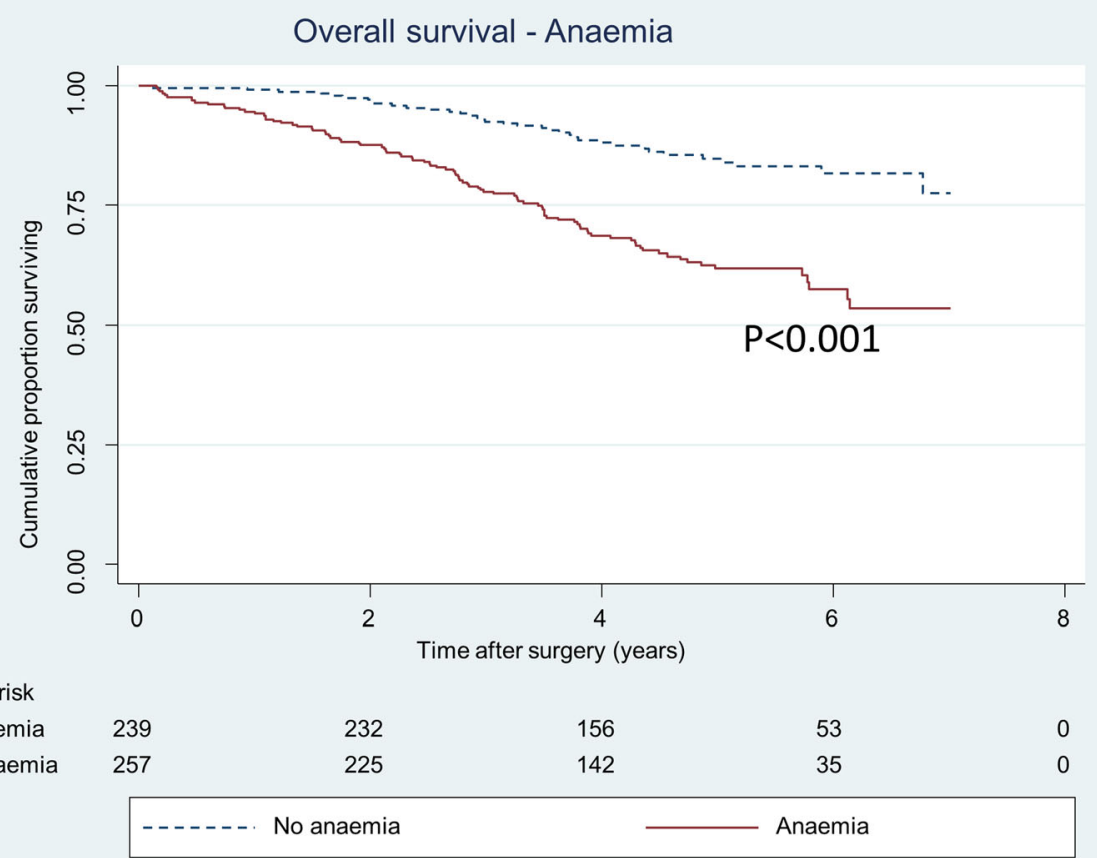

in this study received these presumably less immunemodulatory blood components [23]. In addition, one must also consider the possibility of our study being under powered. While this may be indicated by the comparatively low statistical precision it must be kept in mind that the upper confidence interval for the
Fig. 4 Proportion of patients, operated for CRC stages I-III, alive divided in patients receiving blood transfusion within a day before or after surgery or not. $p$ value represents log-rank test

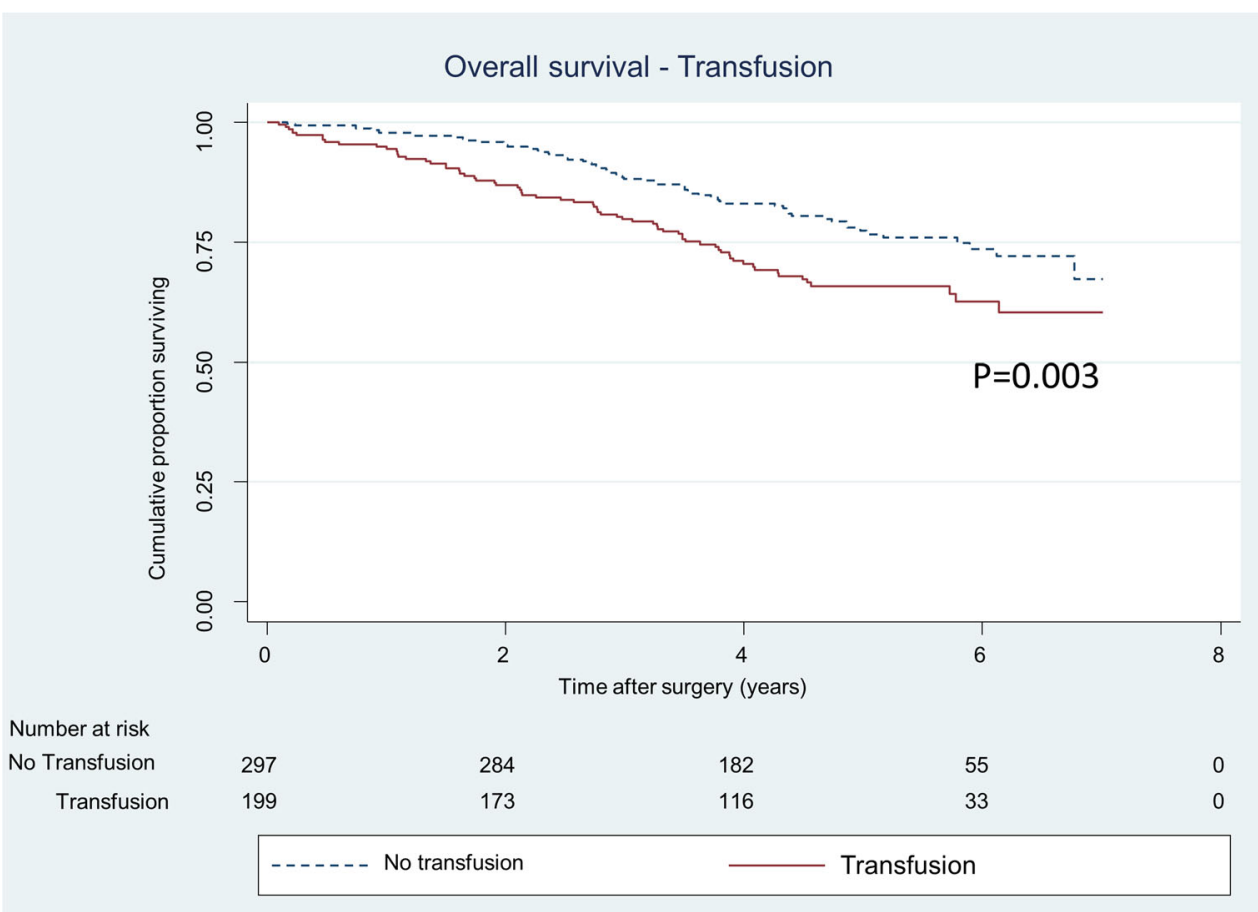


estimate of the effect of blood transfusion on the risk for recurrence was 1.3. This would imply a lesser effect than that derived in the previous meta-analyses $[10,23]$.

\section{Conclusion}

Preoperative anaemia, present in almost half of our CRC patients, was strongly associated with increased risk for overall mortality but not for recurrence. Blood transfusion was not associated with increased risk for recurrence or mortality.

Compliance with ethical standards All procedures performed in studies were in accordance with the ethical standards of the institutional and/ or national research committee and with the 1964 Helsinki declaration and its later amendments or comparable ethical standards. Ethics approval was obtained from the Regional Ethics Committee in Stockholm (2012/784-31/1, 2014/354-32, and 2014/950-32). Informed consent was obtained from the participants when entered into the SCRCR.

Conflict of interest The authors declare that they have no conflicts of interest. Grants were received from The Bengt Ihre Foundation (SLS247641 and SLS-327911) and ALF funding (SLL 20120046 and SLL 20130164). M Mörner received a scholarship from The Swedish Society of Medicine SLS-512621 covering costs for the travel to Denmark during MASCC 2015.

Podium Abstract at MASCC, Copenhagen, Denmark, June 25-27, 2015. Oral presentation 2015-06-26.

Open Access This article is distributed under the terms of the Creative Commons Attribution 4.0 International License (http:// creativecommons.org/licenses/by/4.0/), which permits unrestricted use, distribution, and reproduction in any medium, provided you give appropriate credit to the original author(s) and the source, provide a link to the Creative Commons license, and indicate if changes were made.

\section{References}

1. Sadahiro S, Suzuki T, Tokunaga N, Mukai M, Tajima T, Makuuchi H, Saito T (1998) Anemia in patients with colorectal cancer. J Gastroenterol 33(4):488-494

2. Edna TH, Karlsen V, Jullumstro E, Lydersen S (2012) Prevalence of anaemia at diagnosis of colorectal cancer: assessment of associated risk factors. Hepato-Gastroenterology 59(115):713-716. doi:10.5754/hge11479

3. Ludwig H, Van Belle S, Barrett-Lee P, Birgegard G, Bokemeyer C, Gascon P, Kosmidis P, Krzakowski M, Nortier J, Olmi P, Schneider M, Schrijvers D (2004) The European Cancer Anaemia Survey (ECAS): a large, multinational, prospective survey defining the prevalence, incidence, and treatment of anaemia in cancer patients. Eur $\mathrm{J}$ Cancer 40(15):2293-2306. doi:10.1016/j.ejca.2004.06.019

4. Ludwig H, Muldur E, Endler G, Hubl W (2013) Prevalence of iron deficiency across different tumors and its association with poor performance status, disease status and anemia. Annals of oncology : official journal of the European Society for Medical Oncology / ESMO 24(7):1886-1892. doi:10.1093/annonc/mdt118
5. Jemal A, Bray F, Center MM, Ferlay J, Ward E, Forman D (2011) Global cancer statistics. CA Cancer J Clin 61(2):6990. doi:10.3322/caac.20107

6. Keeler BD, Mishra A, Stavrou CL, Beeby S, Simpson JA, Acheson AG (2016) A cohort investigation of anaemia, treatment and the use of allogeneic blood transfusion in colorectal cancer surgery. Annals of medicine and surgery 6:611. doi:10.1016/j.amsu.2015.12.052

7. Påhlman L CB, Bohe M, Dahlberg M, Öjerskog B, Hallböök O (2008) Kolorektal cancer. Nationellt vårdprogram 2008. Onkologiskt centrum, Umeå, http://www.cancercentrum. $\mathrm{se} / \mathrm{G} 1$ ob a $1 / \mathrm{R} \mathrm{C} \mathrm{C} \mathrm{U} \mathrm{p} \mathrm{p} \mathrm{a} 1$ a Orebro/ V \% c $3 \%$ a 5 rdprocesser/kolorektal/v\%c $3 \%$ a 5 rdprogram $/$ nat vardprogram_08_omvvp_110412.pdf

8. Munoz M, Gomez-Ramirez S, Martin-Montanez E, Auerbach M (2014) Perioperative anemia management in colorectal cancer patients: a pragmatic approach. World journal of gastroenterology : WJG 20(8):1972-1985. doi:10.3748/wjg.v20. i8.1972

9. Goddard AF, James MW, McIntyre AS, Scott BB, British Society of $G$ (2011) Guidelines for the management of iron deficiency anaemia. Gut 60(10):1309-1316. doi:10.1136/gut.2010.228874

10. Amato A, Pescatori M (2006) Perioperative blood transfusions for the recurrence of colorectal cancer. Cochrane Database Syst Rev 1:CD005033. doi:10.1002/14651858. CD005033.pub2

11. Qiu MZ, Yuan ZY, Luo HY, Ruan DY, Wang ZQ, Wang FH, $\mathrm{Li} \mathrm{YH}, \mathrm{Xu} \mathrm{RH}$ (2010) Impact of pretreatment hematologic profile on survival of colorectal cancer patients. Tumour biology : the journal of the International Society for Oncodevelopmental Biology and Medicine 31(4):255-260. doi:10.1007/s13277-010-0024-x

12. Stapley S, Peters TJ, Sharp D, Hamilton W (2006) The mortality of colorectal cancer in relation to the initial symptom at presentation to primary care and to the duration of symptoms: a cohort study using medical records. Br J Cancer 95(10):1321-1325. doi:10.1038/sj.bjc.6603439

13. Zhen L, Zhe S, Zhenning W, Zhifeng M, Zhidong L, Xiaoxia L, Jianguang Y, Huimian X (2012) Iron-deficiency anemia: a predictor of diminished disease-free survival of T3N0M0 stage colon cancer. J Surg Oncol 105(4):371375. doi: $10.1002 /$ jso. 22032

14. Gunnarsson U, Seligsohn E, Jestin P, Pahlman L (2003) Registration and validity of surgical complications in colorectal cancer surgery. The British journal of surgery 90(4): 454-459. doi: $10.1002 /$ bjs. 4058

15. Kodeda K, Nathanaelsson L, Jung B, Olsson H, Jestin P, Sjovall A, Glimelius B, Pahlman L, Syk I (2013) Population-based data from the Swedish Colon Cancer Registry. The British journal of surgery 100(8):1100-1107. doi:10.1002/bjs.9166

16. Halmin M, Bostrom F, Brattstrom O, Lundahl J, Wikman A, Ostlund A, Edgren G (2013) Effect of plasma-to-RBC ratios in trauma patients: a cohort study with time-dependent data*. Crit Care Med 41(8):1905-1914. doi:10.1097/CCM.0b013 e31828a3214

17. Ludvigsson JF, Otterblad-Olausson P, Pettersson BU, Ekbom A (2009) The Swedish personal identity number: possibilities and pitfalls in healthcare and medical research. Eur J Epidemiol 24(11):659-667. doi:10.1007/s10654-009-9350-y

18. WHO (2011) WHO - Haemoglobin concentrations for the diagnosis of anaemia and assessment of severity. Vitamin and Mineral Nutrition Information System

19. Herndon JE 2nd, Harrell FE Jr (1995) The restricted cubic spline as baseline hazard in the proportional hazards model with step function time-dependent covariables. Stat Med 14(19):2119-2129 
20. Roshani D, Ghaderi E (2016) Comparing smoothing techniques for fitting the nonlinear effect of covariate in Cox models. Acta informatica medica : AIM : journal of the Society for Medical Informatics of Bosnia \& Herzegovina : casopis Drustva za medicinsku informatiku BiH 24(1):38-41. doi:10.5455/aim.2016.24.38-41

21. Law WL, Chu KW (2004) Abdominoperineal resection is associated with poor oncological outcome. The British journal of surgery 91(11):1493-1499. doi:10.1002/bjs.4723
22. Jestin P, Nilsson J, Heurgren M, Pahlman L, Glimelius B, Gunnarsson U (2005) Emergency surgery for colonic cancer in a defined population. The British journal of surgery 92(1):94-100. doi:10.1002/bjs.4780

23. Brand A (2002) Immunological aspects of blood transfusions. Transpl Immunol 10(2-3):183-190

24. Amato AC, Pescatori M (1998) Effect of perioperative blood transfusions on recurrence of colorectal cancer: meta-analysis stratified on risk factors. Dis Colon rectum 41(5):570-585 